\title{
Practical Design of a Load Compensation Active Conditioner
}

\author{
Jaime Prieto, Patricio Salmerón, Reyes S. Herrera \\ Department of Electrical Engineering \\ E.P.S. La Rábida, Huelva University \\ Ctra. Palos de la Frontera s/n, E21819 Palos de la Frontera, Huelva (Spain) \\ Phone/Fax number:+0034959017574/7304,jpthomas@uhu.es, patricio@uhu.es, reyes.sanchez@die.uhu.es
}

\begin{abstract}
This paper presents the obtained experimental results with a single-phase experimental prototype of a Load Compensation Active Conditioner, sLCAC. The sLCAC is composed by a series - parallel combination of active power filters, and its main objective is the global conditioning of a load against harmonic distortion. On the one hand, to isolate the load voltage $v_{L}$ from the harmonics in the supply voltage $v_{S}$, as well as to regulate it to the nominal value. On the other hand, to improve the supply current $i_{S}$, compensating the harmonic and reactive components of the load current $i_{L}$. An experimental prototype has been implemented, and the obtained results are presented to support the performance of the proposed design.
\end{abstract}

Key words: Power active filters, harmonic distortion, power conditioning, UPQC, power quality.

\section{Introduction}

The widespread and increasing use of power electronic loads is giving each day more importance to the concept of Electric Power Quality, EPQ. These loads increase substantially the distortion level in the power grids and at the same time they use to be sensible to this distortion. A proper conditioning of these loads has mainly two targets: On the one hand, to survey a load voltage $v_{L}$ sinusoidal, balanced and regulated to its nominal value; independently of the conditions of the supply voltage $v_{S}$. On the other hand, the supply current $i_{S}$ must be also sinusoidal and balanced, with the minimum value to transfer the electric power. This way, the conditioned load is not affected by the voltage distortion produced by nearby loads; and its distorted load current $i_{L}$ does not affect those loads that are connected in the same feeder.

Among the practical solutions to this problem are the Active Power Filters, APF [1]. Their first applications were focused to compensate the harmonic components of the load current. Later, they were developed to compensate wider targets like the reactive and unbalance components, receiving then the denomination of Active Power Line Conditioner, APLC [1]. Although, the emphasis must be focused in the Unified Power Quality Conditioners, UPQC [2-8], which integrate in one module a combination of series and parallel APFs. Both converters are necessary because of the exposed reasons in the last paragraph, for a complete and generic load conditioning.
This paper presents the experimental results obtained with an experimental prototype of a single-phase Load Compensation Active Conditioner, sLCAC [8]. The SLCAC is composed by a series - parallel combination of active power filters, and its main objective is the global conditioning of a load against harmonic distortion: to isolate the load voltage $v_{L}$ from the harmonics in the supply voltage $v_{S}$, as well as to regulate it to the nominal value; and also to improve the supply current $i_{S}$, compensating the harmonic and reactive components of the load current $i_{L}$.

As the main target of this paper is the laboratory prototype and the experimental results, the items will be exposed in the following order: In section 2, the components of the experimental prototype will be described. In section 3, the control strategy as well as the practical adaptations will be explained. Section 4 will show the criteria for the selection of the practical cases; and section 5 will present the obtained experimental results. Finally, section 6 will expose the derived conclusions of this work.

\section{Experimental Prototype}

The power circuit of the sLCAC is shown in fig. 1. It is composed of a series and a shunt converter with a common DC link. The position of their respective matching transformers $\mathrm{T}_{\mathrm{S}}$ and $\mathrm{T}_{\mathrm{P}}$ can be observed, as well as the passive elements for the high frequency filtering. It also shows the situation of the main magnitudes and the measuring points needed for the control of the conditioner. The DC side of the SLCAC is made of two split capacitors, and each converter can be made with only one branch of power transistors.

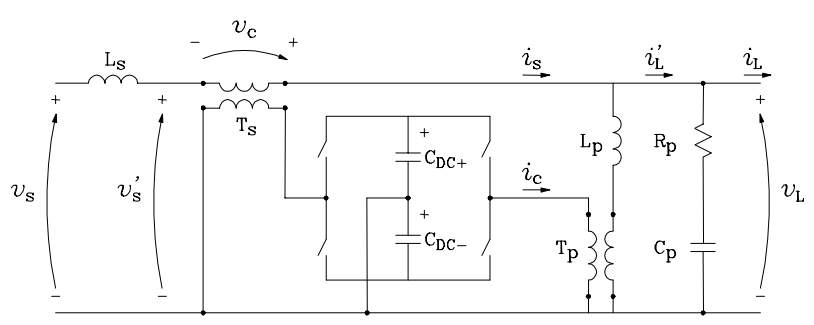

Fig. 1. Power circuit of the sLCAC.

The experimental prototype has a nominal power of $0.25 \mathrm{kVA}$, at $115 \mathrm{Vrms}, 50 \mathrm{~Hz}$. The converters are made with two Semikron SKM50GB123D branches of two 
IGBTs with anti - parallel diodes, assembled in a set with the capacitors $\mathrm{C}_{\mathrm{DC}+}$ and $\mathrm{C}_{\mathrm{DC}-}$ of $2200 \mu \mathrm{F}, 400 \mathrm{~V}$ each one. Figure 2 shows the module with the converters and the DC capacitors. Behind it, a coupling transformer and an inductance can also be observed.

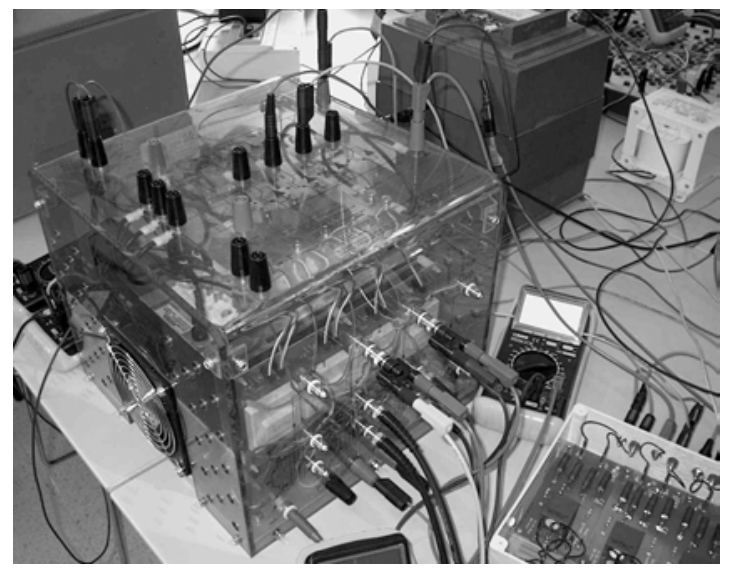

Fig. 2. Module with IGBT Converters and DC capacitors.

The coupling transformer $T_{P}$ has been selected with a turn ratio of $1: 2$, and the voltages of the DC capacitors are set at $\pm 125 \mathrm{~V}$. Thus, the voltage downstream $\mathrm{L}_{\mathrm{P}}$ will be between $\pm 250 \mathrm{~V}$ peak; that is between the usual values of 1.5 and 2 times the peak value of the supply voltage (115 Vrms) to allow the parallel converter to track appropriately the compensating current $i_{C}$.

The series compensating voltage is a $25 \%$ of the voltage of the parallel converter. With a series transformer $\mathrm{T}_{\mathrm{S}}$ with a turn ratio of $2: 1$, the voltage $v_{C}$ can be regulated approximately between $\pm 62.5 \mathrm{~V}$ peak.

The rest of passive components have been selected according to the criteria exposed in [8] and their values are shown in table I.

TABLE I. - Passive Components of the sLCAC.

\begin{tabular}{|c|c|c|c|c|c|}
\hline $\mathrm{L}_{\mathrm{S}}$ & $\mathrm{T}_{\mathrm{S}}$ & $\mathrm{L}_{\mathrm{P}}$ & $\mathrm{T}_{\mathrm{P}}$ & $\mathrm{R}_{\mathrm{P}}$ & $\mathrm{C}_{\mathrm{P}}$ \\
\hline $50 \mathrm{mH}$ & $230 / 115 \mathrm{~V}$ & $50 \mathrm{mH}$ & $115 / 230 \mathrm{~V}$ & $2.5 \Omega$ & $30 \mu \mathrm{F}$ \\
\hline
\end{tabular}

The sLCAC is controlled by a DSP acquisition and control board dSPACE DS1104. It manages the switching of the IGBTs, with the inputs signals of the voltage and current measurements of the system. They are taken with Hall effect sensors LEM LA35 - NP for the currents and LEM LV25 - 600 for the voltages. Figure 3 shows a measurement set, with three voltage and four current sensors. Figure 4 shows the computer with the installed dSPACE board, and the monitoring program. This real - time systems works at a sampling and control time of $60 \mu \mathrm{s}$, that means a switching frequency around $16.6 \mathrm{kHz}$.

\section{Control of the sLCAC}

The control method used is an adaptation for single phase systems of the method proposed by the authors in [8]. The series converter works as a controlled voltage source, which compensates the components that makes the load voltage different of an ideal sinusoidal and regulated voltage.

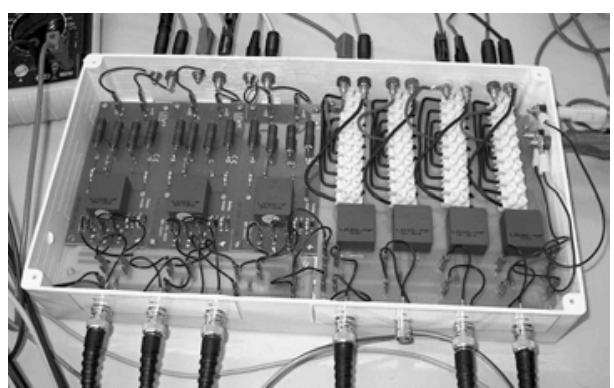

Fig. 3. Voltage and current sensors.

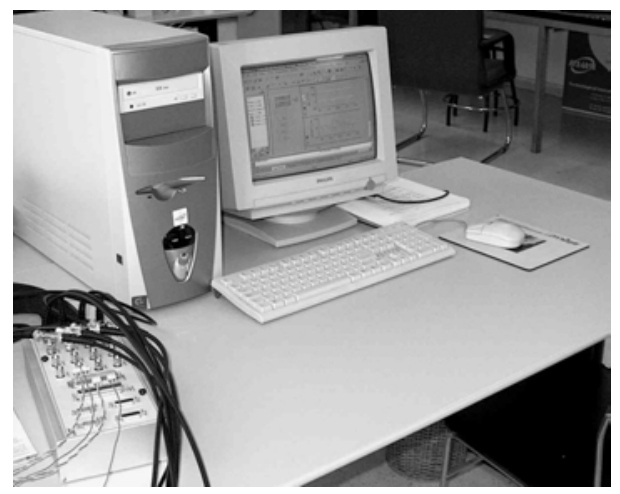

Fig. 4. Monitoring computer and dSPACE DS1104 Board.

The shunt converter, placed downstream, works as a controlled current source and has the function of eliminating the harmonic and reactive components of the load current. Each filter has a specialised function trough a unified control that treats globally the load compensation process. Thus, the voltage waveform that drives the shunt converter control for determining the compensation current, is the reference obtained for the series filter control. Besides, as it will be explained later, each converter controls both targets - the load voltage and the supply current - with a coupling control that gives the final design a great robustness and an enhanced behaviour.

\section{A. Load voltage reference $\left(v_{L} *=v_{l, \text { reg }}\right)$}

The series filter control looks for an ideal reference voltage supply: a regulated voltage without distortion. Fig. 5 shows the block diagram of this part of the control circuit. The fundamental component of the supply voltage is selected trough a bandpass filter, and in a second stage a control loop regulates the rms value of $v_{I}$ to a pre-set value $\mathrm{V}_{\mathrm{REF}}$. The selection of the bandwidth of the bandpass filter $\left( \pm 2 \% f_{N}\right)$ is oriented to attenuate fast voltage amplitude variations. The combination with the amplitude control loop allows an accurate voltage regulation.

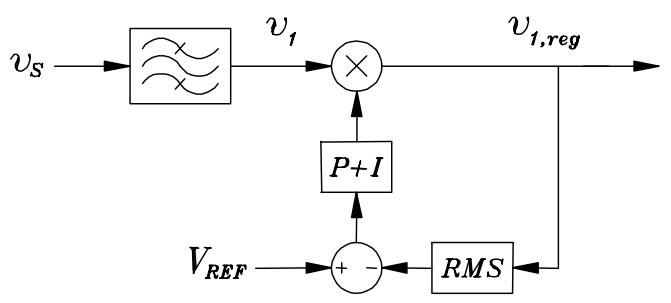

Fig. 5. Block diagram for the calculation of the load voltage reference $v_{L}^{*}$. 


\section{B. Supply current reference $\left(i_{S} *=i_{a}+i_{a C}\right)$}

The shunt filter control is based on the calculation of the active load current $i_{a}$, and its block diagram is shown in fig. 6 . The current reference $i_{S} *$ will be basically this active load current, and it is obtained from the calculation of the active load current using the load voltage reference $v_{1, \text { reg. }}$

The transfer of an active power $P$ from the supply to the load requires the line current $i_{S}$ to be in phase with the voltage, through a proportional constant that is related with the active power and the voltage rms value (1). This formulation corresponds with the time average compensation mode in [9].

$$
i_{a}=\frac{P}{V^{2}} v
$$

where $V$ is the voltage rms value.

The difference between the load current $i_{L}$ and the active component $i_{a}$ determinates the components that do not transport useful power and therefore are compensable $\left(i_{C L} *=i_{L}-i_{a}\right)$.

The determination of the active power requires a lowpass filter to eliminate the oscillatory components of the instantaneous power $p(t)$. Using an integral feedback loop it is possible to reach, in steady state, to some values of $i_{C}$ whose average power $P_{C}$ is null. Therefore, the output of the integrator remains without change in the previous estimated value of $G_{L}\left(P / V^{2}\right)$. This will be the state until the load changes. The adaptation speed against load variations depends mainly on the dynamic response of the set lowpass filter + integrator.

The second function of the shunt converter is to maintain the power balance and the capacitors voltages inside the sLCAC. With this criterion, the estimated power flow through the series converter is included in $P_{C}$, as the product of the references of the compensating voltage $v_{C} *$ and the supply current $i_{S} *$.

A direct control of the voltage in the DC side is also included in the control loop. This last component is necessary to compensate the internal losses of the conditioner. The measurement of the capacitors voltages is unavoidable in a practical implementation, because any small difference in the estimated power balance or errors in the measurements could imply a slow but constant variation of the energy stored in the DC side. The internal losses of the sLCAC suppose an additional component of the active current, $i_{a C}$. This component is included to the supply and compensating current references after the main loop of the load active current calculation, so it does not modify the average power of the main circuit.

\section{Passive components behaviour}

The IGBT converters can not track accurately the compensating signals references with harmonics higher than $f_{C} / 10$, where $f_{C}$ is the maximum switching frequency. These components should be filtered by means of passive elements, like inductances and capacitors. Besides, many of these high frequency harmonics are generated by the converters themselves. On the other hand, the passive components should interfere the least possible with the tasks of the IGBT converters at low frequencies, mainly to maintain the efficiency.

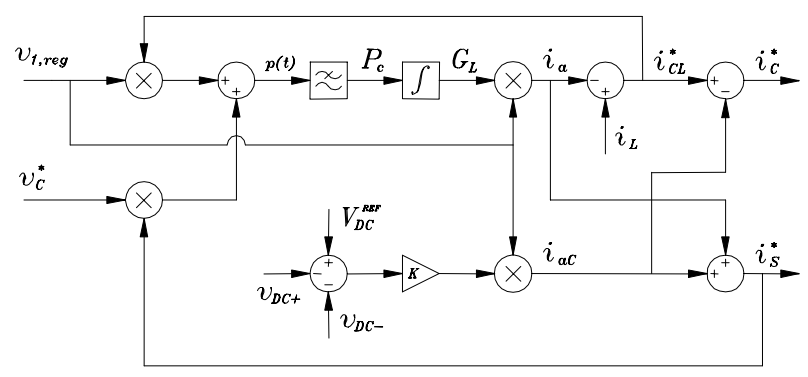

Fig. 6. Block diagram for the calculation of the supply current reference $i_{S}{ }^{*}$ and the compensating current reference $i_{C}{ }^{*}$.

Figure 1 shows the position of these passive elements: $L_{S}, R_{P}$ and $C_{P}$. They deviate the higher harmonics of $i_{C}$ or $i_{L}$ from circulating with $i_{S}$, and also attenuate the effects of the higher harmonics of $v_{S}$ or $v_{C}$ over the load voltage $v_{L}$ or the supply current $i_{S}$.

The behaviour of the passive components can be analysed as a linear n-port network that gives a relation among the voltages and currents of the supply, the load and the converters of the active conditioner. This way, it is possible to evaluate how the distortions that could be present in $v_{C}, i_{C}, v_{S}$ or $i_{L}$ influence the target variables $v_{L}$ and $i_{S}$. This analysis can be made through the state-space equations of the multiport circuit. The eigenvalues of the network show the natural response of the passive components against sudden perturbations, and the transfer functions between the target variables and the sources of distortion show the attenuation or increment of these distortions at every frequency.

This analysis has been made, with the technique exposed in [8], to select the values of the passive components of the prototype. They show a correct attenuation of the harmonics higher than $f_{C} / 10$, but present a strong resonance at $130 \mathrm{~Hz}$, with a slow transient response (See eigenvalues in left column of table II).

\section{Control enhancement}

It is difficult to avoid these type of resonances when the passive components must be dissipative the least possible. To enhance the behaviour of the sLCAC in the range of the controllable frequencies, the basic control is modified with two coupling correcting signals proportional to the deviation of the targets respect to the control values, but applied in the opposite converter that should control them. Thus, the definitive compensating references are:

$$
\begin{aligned}
& v_{C}^{*}=v_{C} * *+R\left(i_{S}^{*}-i_{S}\right) \\
& i_{C} *=i_{C} * *+G\left(v_{L} *-v_{L}\right)
\end{aligned}
$$

where $v_{C} * *$ and $i_{C}{ }^{* *}$ are the calculated references already explained in the subsections A and B. The first terms will actuate as a predictive control, and the second terms of the references will actuate as a corrective control. 
The effect of this additional control can be analysed including this control law in the state-space equations and recalculating the transfer functions and eigenvalues. The right column of table II shows the corresponding eigenvalues with $R=500$ and $G=0.1$, where enough fast transients responses and a good attenuation can be expected.

This control enhancement does not only fit the problem of the passive filtering. It also provides a very robust control of the conditioner. For instance, it is not necessary to know the precise values of the passive components, or to include the equivalent circuit of the coupling transformers.

If both converters track their respective references, only a small amount of the corrective crossed signals will be necessary. But when it is not possible, the saturated converter is helped by the other one, tracking both targets to their control references as fast as possible with a stable behaviour.

TABLE II. - Eigenvalues of the passive network, and with the enhanced control.

\begin{tabular}{|l|}
\hline Eigenvalues of $\mathbf{A}\left(\mathbf{s}^{-1}\right)$ \\
\hline$-26 \pm 816 \mathrm{j}(130 \mathrm{~Hz})$ \\
\hline$-26 \pm 816 \mathrm{j}(130 \mathrm{~Hz})$ \\
\hline
\end{tabular}

\begin{tabular}{|c|}
\hline $\begin{array}{c}\text { Eigenvalues of } \mathbf{A}\left(\mathbf{s}^{-1}\right) \\
\text { with the enhanced control }\end{array}$ \\
\hline$-9,982$ \\
\hline$-4,498$ \\
\hline
\end{tabular}

\section{E. Switching control}

The switching control of the converters is based on the compensating signals $v_{C} *, i_{C} *$ generated by the sLCAC control. In the series converters, the compensating voltage $v_{C}$ is built with a PWM generator, with a pulse width calculated at each sampling time as:

$$
\frac{t_{S}}{T}=\frac{2 v_{C}^{*}+v_{D C-}}{v_{D C+}+v_{D C-}}
$$

where $T$ is the sampling time of the control system, and $v_{D C+}$ and $v_{D C \text { - }}$ are the voltages of the DC side capacitors. The scale factor 2 is due to the turn ratio of the series transformer $\mathrm{T}_{\mathrm{S}}$.

In the shunt converters the compensating current $i_{C}$ is built with a periodic sampling current control. At each sampling time, one of the IGBTs of the shunt converter will be switched on in the whole interval, as a function of the sign of the difference between the measured compensating current $i_{C}$ and the reference $i_{C}{ }^{*}$ :

$$
\frac{t_{P}}{T}=\operatorname{sign}\left(2 i_{C}^{*}-i_{C}\right) \quad \in[0,1]
$$

Here also the scale factor 2 is due to the turn relation of the shunt transformer $\mathrm{T}_{\mathrm{P}}$. Although the current control is not the best one, both methods - for voltage and current provide a limited switching frequency of the converters; and the experimental results will show the robustness of the control strategy adopted.

\section{Practical Cases}

Due to the wide load range target aimed in the design of the sLCAC, two different types of load have been selected as a behaviour test. The first case load is a full bridge diode rectifier with a high capacitance in the DC side and a smoothing inductance in the AC side. This load, Voltage Rectifier, is a characteristic harmonic voltage source [10]. The second case load is also a full bridge diode rectifier, this time with a high inductance in the DC side, Current Rectifier, that is a typical harmonic current source [10]. The value of the load resistance has been adjusted to get a similar active power consumption, around $200 \mathrm{~W}$, in both cases.

In the experimental power system, the supply is a variable autotransformer of $230 / 0-230 \mathrm{~V}, 25 \mathrm{~A}, 50 \mathrm{~Hz}$, directly fed from the power grid, with an output voltage adjusted to $115 \mathrm{~V}$ at no - load state.

\section{Experimental Results}

The measurements of the tests have been acquired with a FLUKE 43 Power Quality Analyser. The obtained results are shown in fig. 7 to 12 , and the main values are summarised in tables III and IV. Voltage and current waveforms before and after compensation are presented, as well as THD, active power and power factor measurements.

\section{A. Case 1}

Figures 7 to 9 show the measurements corresponding to the first case, the Voltage Rectifier load. Figure 7 presents the waveforms and values of the load voltage and current before compensation. Figure $7 \mathrm{a}$ are the waveforms of the voltage and the current, fig. $7 \mathrm{~b}$ shows the powers and power factor measurements, fig. $7 \mathrm{c}$ the harmonic spectrum of the voltage, and fig. $7 \mathrm{~d}$ the harmonic spectrum of the current.

Figures 8 and 9 show after compensation the same type of measurements, for the supply side and load side respectively. Table III summarises the main values obtained for this case.

TABLE III: Measurements for the Voltage Rectifier Load Case.

\begin{tabular}{|c|c|c|c|c|c|c|}
\hline & $\begin{array}{c}\mathrm{Vx} \\
\left(\mathrm{V}_{\mathrm{rms}}\right)\end{array}$ & $\begin{array}{c}\text { THDv } \\
(\%)\end{array}$ & $\begin{array}{c}\mathrm{Ix} \\
\left(\mathrm{A}_{\mathrm{rms}}\right)\end{array}$ & $\begin{array}{c}\text { THDi } \\
(\%)\end{array}$ & $\begin{array}{c}\mathrm{Px} \\
(\mathrm{W})\end{array}$ & $\begin{array}{c}\mathrm{FP} \\
(-)\end{array}$ \\
\hline $\begin{array}{c}\text { Load before } \\
\text { comp. }\left(V_{L}, I_{L}\right)\end{array}$ & 110.1 & 3.1 & 2.03 & 26.7 & 190 & 0.81 \\
\hline $\begin{array}{c}\text { Supply side after } \\
\text { comp. }\left(V_{S}, I_{S}\right)\end{array}$ & 112.6 & 1.8 & 2.01 & 1.2 & 230 & 1.00 \\
\hline $\begin{array}{c}\text { Load side after } \\
\text { comp. }\left(V_{L}, I_{L}\right)\end{array}$ & 113.8 & 1.8 & 2.16 & 27.7 & 200 & 0.81 \\
\hline
\end{tabular}

Before compensation, the load voltage $v_{L}$ suffers a voltage drop of $4.3 \%$ mainly by the effect of the supply source impedance. The nature of the load generates also a voltage distortion of $3.1 \%$. After compensation, the load voltage is closer to its ideal value, with a voltage drop of $1.04 \%$ and a distortion of $1.8 \%$. The supply voltage $v_{S}$ also reflects the effect of the compensation, due to the enhanced supply current. The THD value of $1.8 \%$ can be caused by the own compensation process as well as by the existing distortion in the supply network, that has different values depending on the day or even the hour when the test have been made, with variations in a range from 0.7 to $2.5 \%$. 
a)

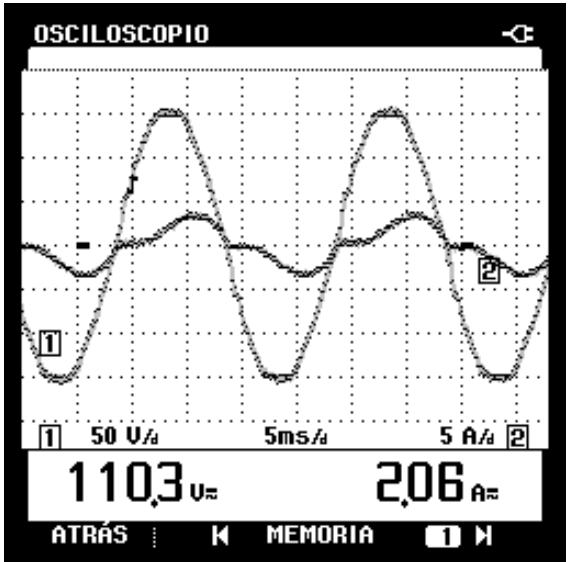

b)

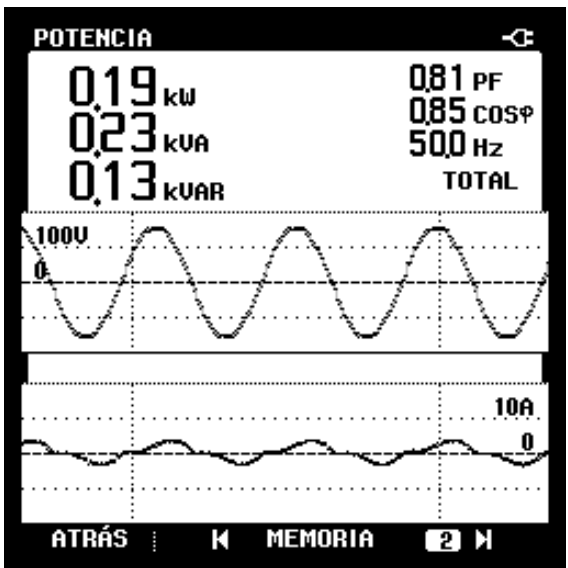

c)

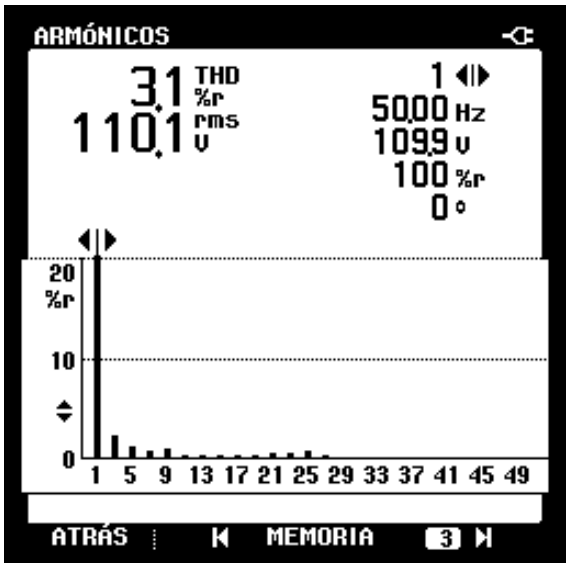

d)

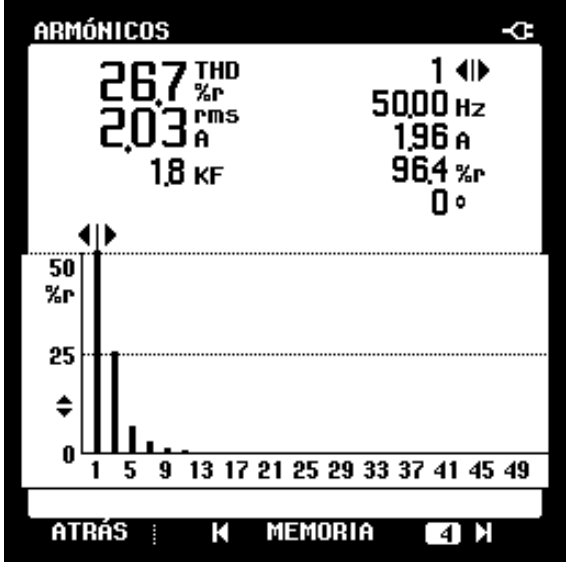

Fig. 7. Measurements of the load voltage $v_{L}$ and current $i_{L}$ before compensation, for the Voltage Rectifier load case:

a) waveforms, b) active, reactive and apparent powers,

c) voltage harmonic spectrum, d) current harmonic spectrum.

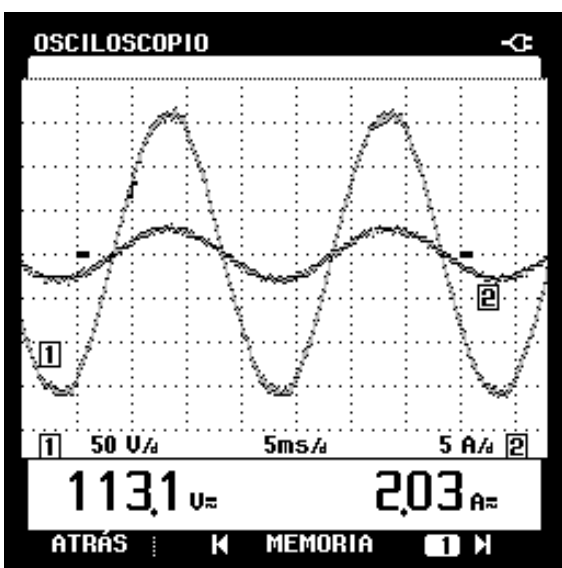

a)

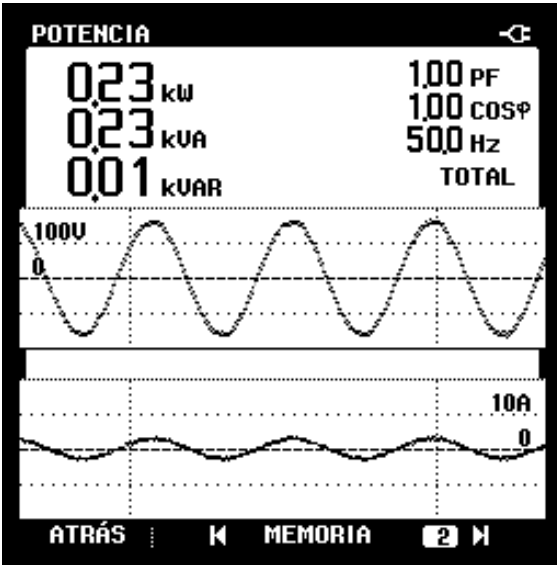

b)

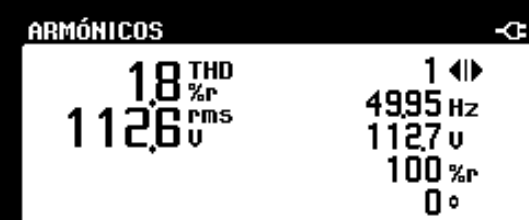

c)

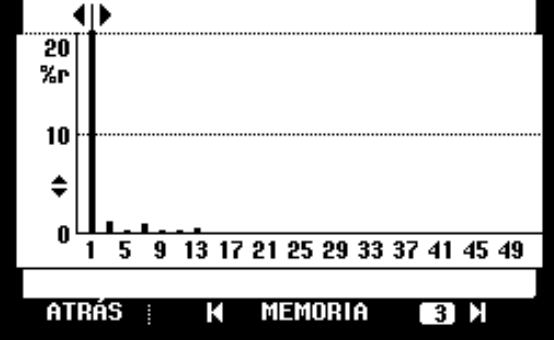

d)

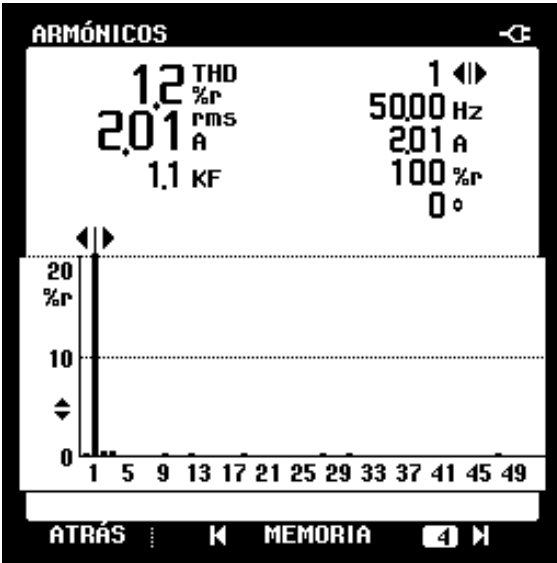

Fig. 8. Measurements of the supply voltage $v_{S}$ and current $i_{S}$ after compensation, for the Voltage Rectifier load case: a) waveforms, b) active, reactive and apparent powers, c) voltage harmonic spectrum, d) current harmonic spectrum. 
a)

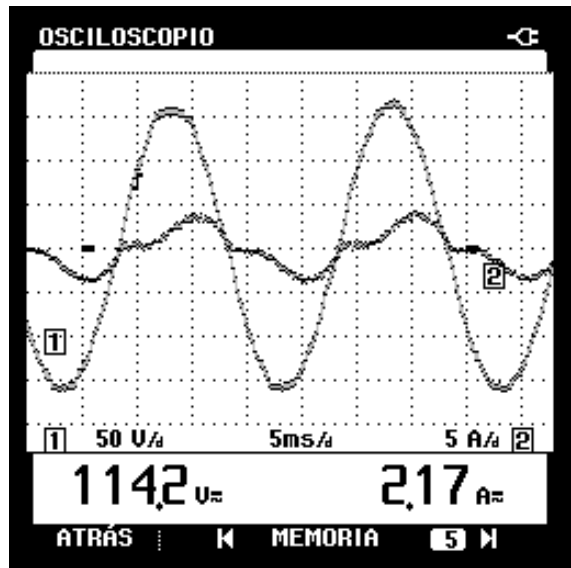

b)
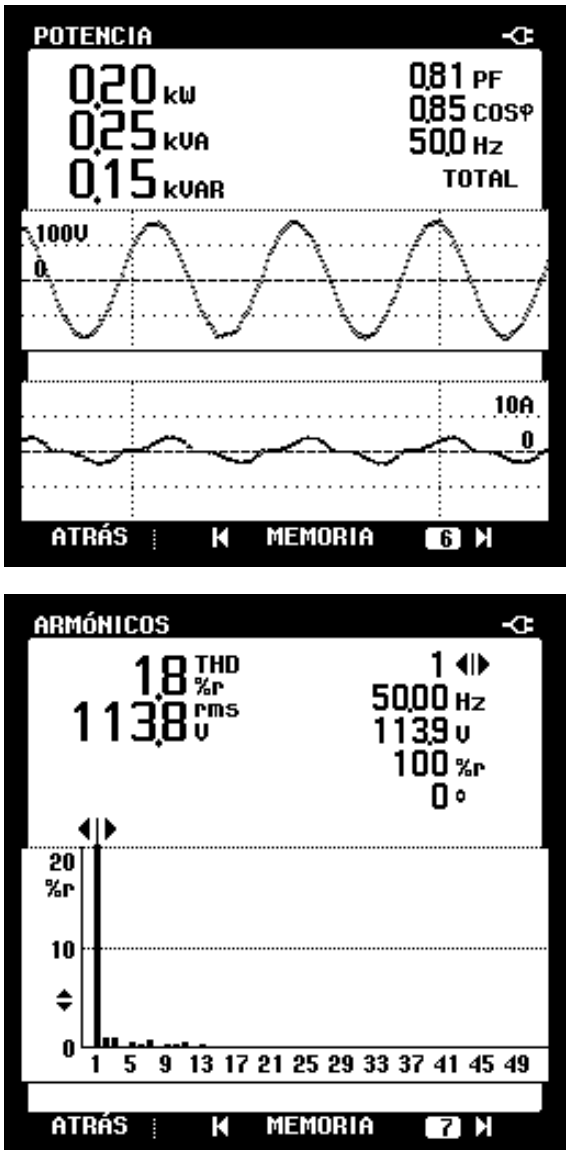

c)

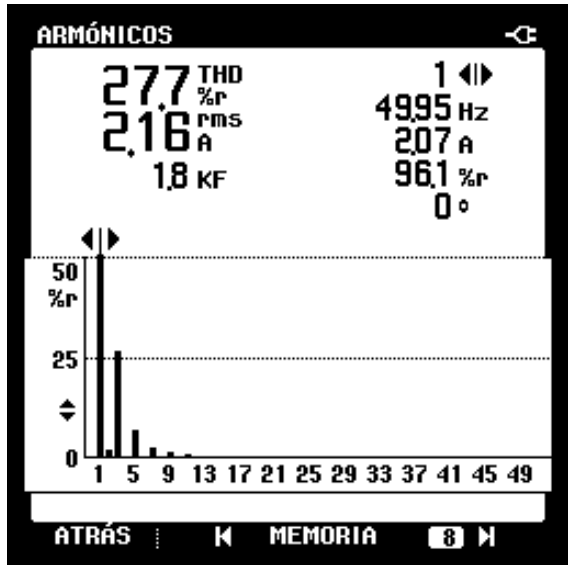

Fig. 9. Measurements of the load voltage $v_{L}$ and current $i_{L}$ after compensation, for the Voltage Rectifier load case: a) waveforms, b) active, reactive and apparent powers,

c) voltage harmonic spectrum, d) current harmonic spectrum.
With regards to the currents, before compensation the load draws a current of $2.03 \mathrm{~A}$ with a distortion of $26.7 \%$. After compensation, the rms value of this current increments to $2.16 \mathrm{~A}$ with a THD of $27.7 \%$. This increase of both values is mainly due to a better regulation and more ideal behaviour of load voltage.

On the other side, the supply current $i_{S}$ after compensation is practically sinusoidal and in phase with the supply voltage, with the minimum rms value to transfer the necessary active power for the load and the losses of the conditioner.

The active power demanded by the load increases slightly after compensation, from 190 to $200 \mathrm{~W}$, due to the enhancement of the load voltage. And the power factor is practically the unity. The comparison of the active powers between the input and output of the conditioner allows to calculate its efficiency for this case in a value of $87.0 \%$.

\section{B. Case 2}

Figures 10 to 12 and table IV shows the obtained results for the second case of the Current Rectifier load, with the same structure of the first case. The comments that can be made for the second case are very similar to the previous case.

TABLE IV: Measurements for the Current Rectifier Load Case.

\begin{tabular}{|c|c|c|c|c|c|c|}
\hline & $\begin{array}{c}\mathrm{Vx} \\
\left(\mathrm{V}_{\mathrm{rms}}\right)\end{array}$ & $\begin{array}{c}\mathrm{THDV} \\
(\%)\end{array}$ & $\begin{array}{c}\mathrm{Ix} \\
\left(\mathrm{A}_{\mathrm{rms}}\right)\end{array}$ & $\begin{array}{c}\text { THDi } \\
(\%)\end{array}$ & $\begin{array}{c}\mathrm{Px} \\
(\mathrm{W})\end{array}$ & $\begin{array}{c}\mathrm{FP} \\
(-)\end{array}$ \\
\hline $\begin{array}{c}\text { Load before } \\
\text { comp. }\left(V_{L}, I_{L}\right)\end{array}$ & 111.0 & 3.4 & 1.92 & 22.9 & 210 & 0.96 \\
\hline $\begin{array}{c}\text { Supply side after } \\
\text { comp. }\left(V_{S}, I_{S}\right)\end{array}$ & 112.3 & 2.2 & 2.32 & 1.0 & 260 & 1.00 \\
\hline $\begin{array}{c}\text { Load side after } \\
\text { comp. }\left(V_{L}, I_{L}\right)\end{array}$ & 114.5 & 5.0 & 1.96 & 25.5 & 220 & 0.95 \\
\hline
\end{tabular}

The voltage regulation at the load side is better than the previous case, but the distortion level increases to 5.0 $\%$. This is because this load is an extreme case, with sharp changes of the load current in the order of its nominal value. This effect can be observed in the commutation instants at the polarity changes of the load voltage (see fig. 10a). In this moments, the shunt converter can not compensate instantaneously this load current change and a short transient is produced, where the load voltage is distorted by the current regulating control of the series inverter.

Although, like in the previous case, the supply current is completely compensated and it reflects also in the quality of the supply voltage. Besides, it can be observed that in this case there is an increment of the supply current respect of the load current. This is due to the different kind of load, as well as the slight decrement of the efficiency to a value of $84.6 \%$.

\section{Conclusions}

The experimental results of a single - phase Load Compensation Active Conditioner prototype are presented. The design of the SLCAC allows to isolate the load voltage from the harmonics of the supply voltage, enhancing also the voltage regulation. 
a)

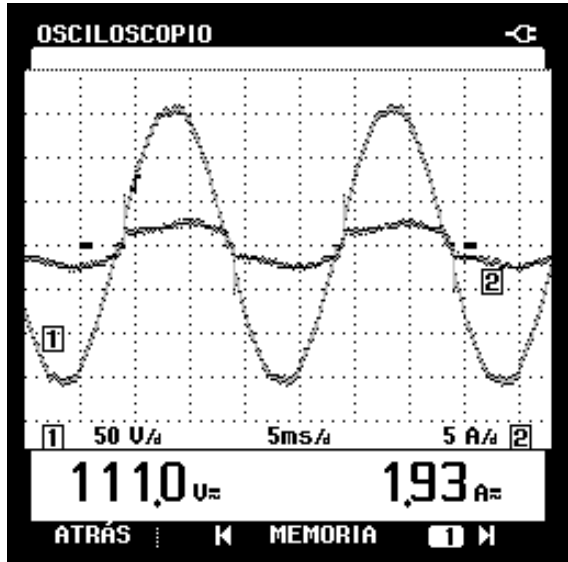

b)

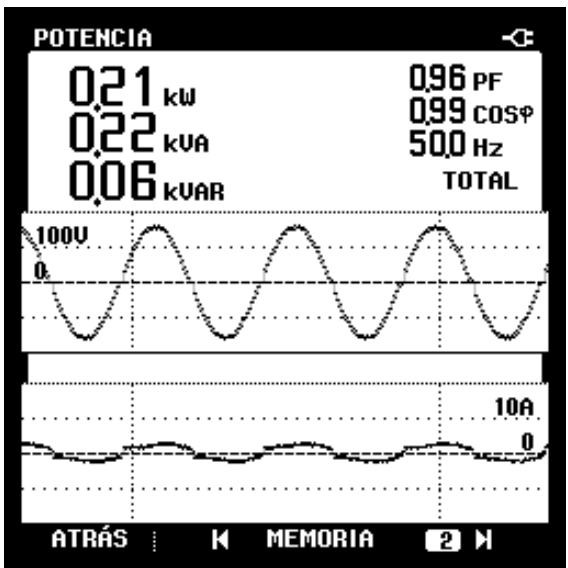

c)

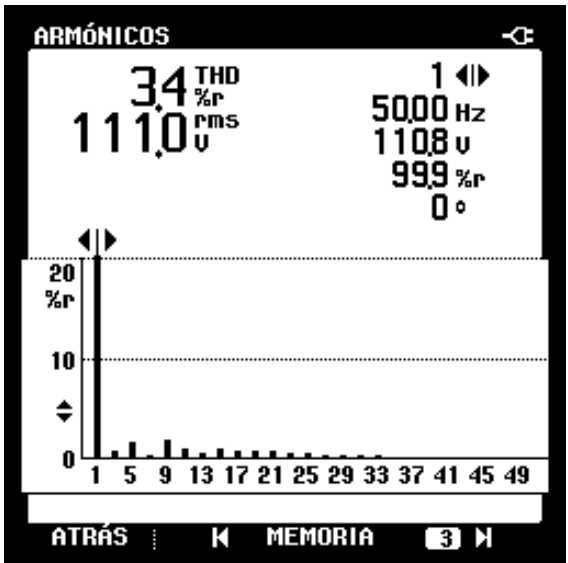

d)

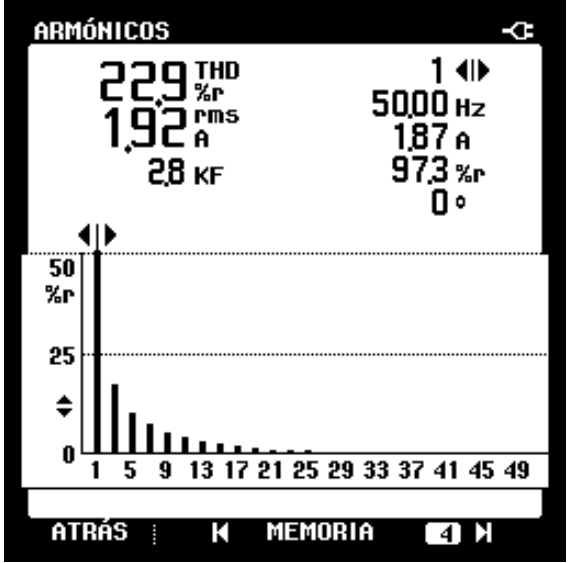

Fig. 10. Measurements of the load voltage $v_{L}$ and current $i_{L}$ before compensation, for the Current Rectifier load case:

a) waveforms, b) active, reactive and apparent powers,

c) voltage harmonic spectrum, d) current harmonic spectrum.

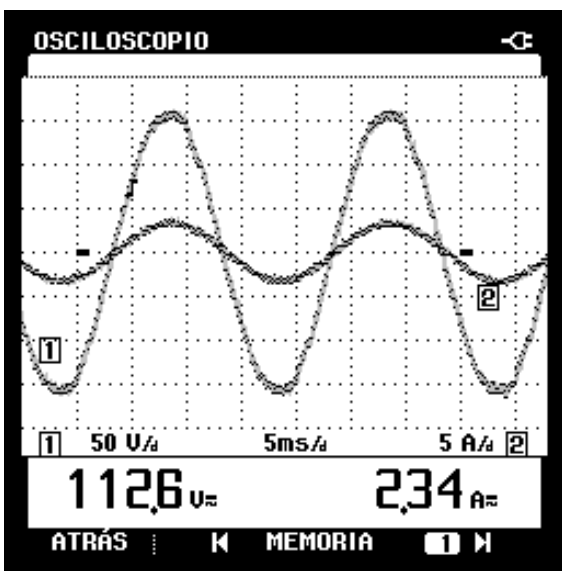

a)

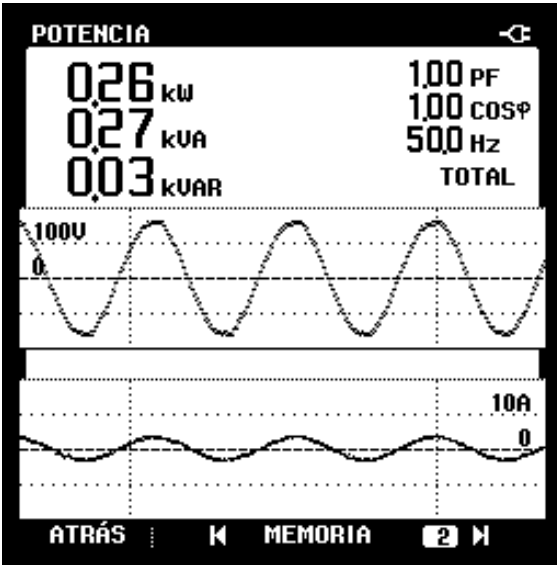

b)

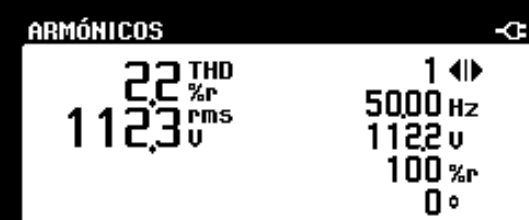

c)

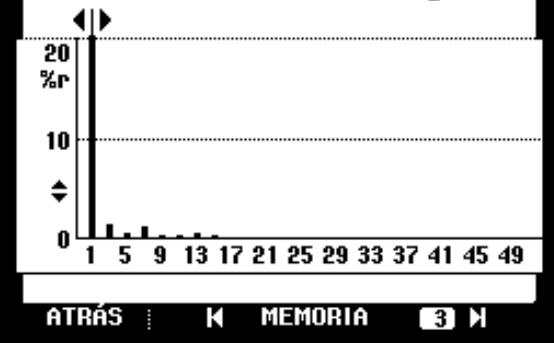

d)

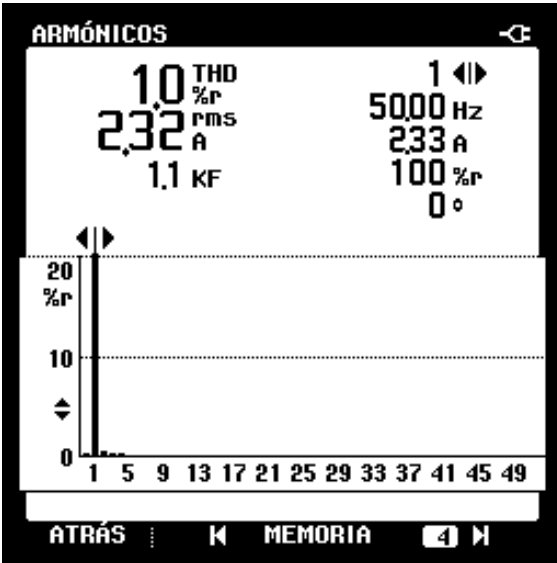

Fig. 11. Measurements of the supply voltage $v_{S}$ and current $i_{S}$ after compensation, for the Current Rectifier load case:

a) waveforms, b) active, reactive and apparent powers,

c) voltage harmonic spectrum, d) current harmonic spectrum. 
a)

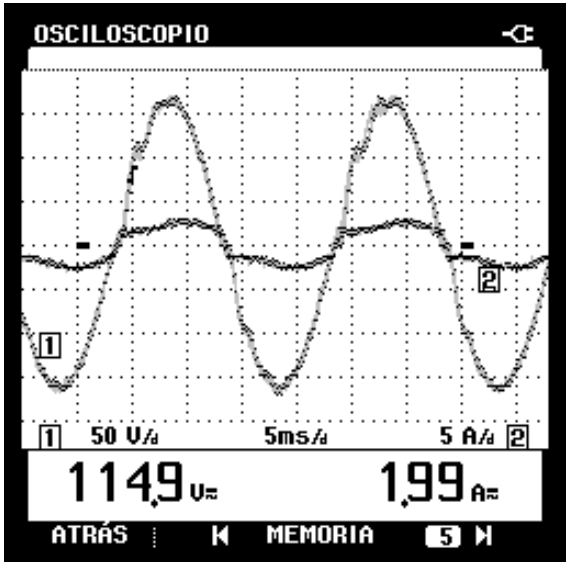

b)
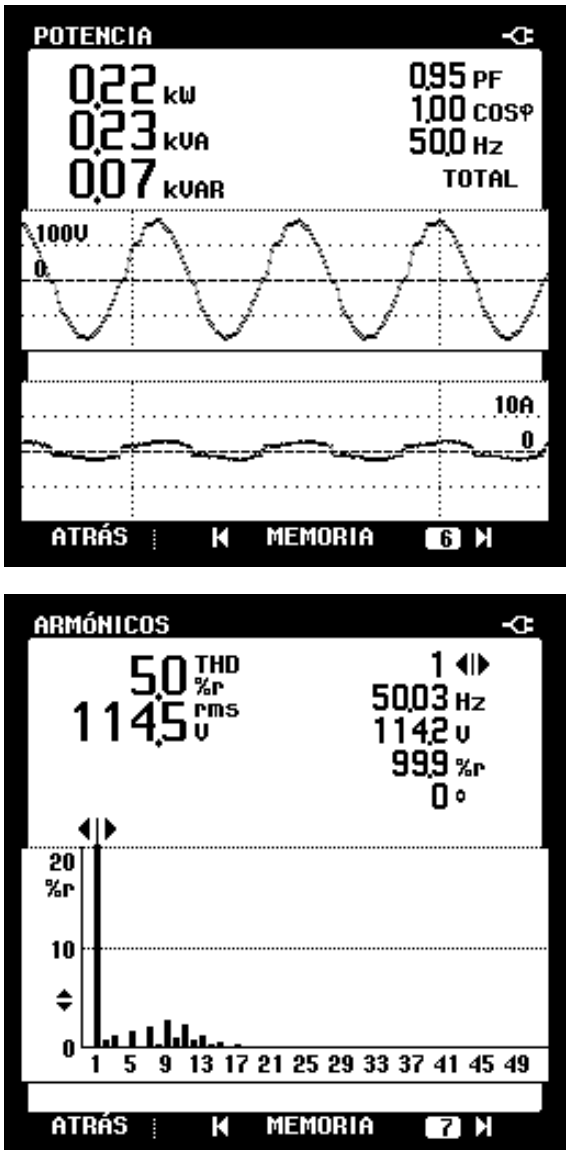

c)

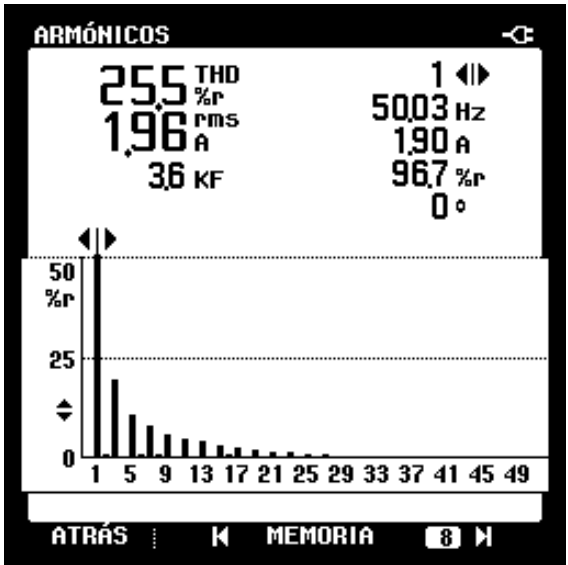

Fig. 12. Measurements of the load voltage $v_{L}$ and current $i_{L}$ after compensation, for the Current Rectifier load case: a) waveforms, b) active, reactive and apparent powers,

c) voltage harmonic spectrum, d) current harmonic spectrum.
It also compensates the reactive and harmonic components of the load current, with the consequent effect on the supply current and voltage. The obtained experimental results with the two types of load support the performance of the proposed design for the development of wide range active conditioning equipment to improve the electric power quality in highly distorted environments.

\section{Acknowledgement}

This work is within the project "Harmonic Distortion Compensation in Electrical Installations using Different Configurations of Active Power Filters." DPI200301336, financed by the CICYT (Ministerio de Ciencia y Tecnología, Spain).

\section{References}

[1] H. Akagi, "New Trends in Active Filters for Power Conditioning," IEEE Trans. Industry Applications, Vol. 32 (6), pp. 1312-1322, Nov. 1996.

[2] H. Akagi and H. Fujita, "A New Power Line Conditioner for Harmonic Compensation in Power Systems," IEEE Trans. Power Delivery, Vol. 10 (3), pp. 153-158, Jul. 1995.

[3] H. Fujita and H. Akagi, "The Unified Power Quality Conditioner: The Integration of Series and Shunt-Active Filters," IEEE Trans. Power Electronics, Vol. 13 (2), pp. 315-322, Mar. 1998.

[4] M. Aredes, K. Heumann, E. H. Watanabe, "An Universal Active Power Line Conditioner," IEEE Trans. Power Delivery, Vol. 13 (2), pp. 545-551, Apr. 1998.

[5] F. Kamran, Thomas G. Habetler, "Combined Deadbeat Control of a Series-Parallel Converter Combination Used as a Universal Power Filter," IEEE Trans. Power Electronics, Vol. 13 (1), pp. 160-168, Jan. 1998.

[6] A. Gosh, G. Ledwich, "A unified power quality conditioner (UPQC) for simultaneous voltage and current compensation," Electric Power Systems Research, Vol. 59, pp. 55-63, 2001.

[7] A. Nasiri, A. Emadi, " Different Topologies for SinglePhase Unified Power Quality Conditioners," in Proc. of the 38th Industry Applications Conf., Vol. 2, pp. 976-981, Oct. 2003.

[8] J. Prieto, P. Salmerón, J. R. Vázquez and J. Alcántara, “A Series - Parallel Configuration of Active Power Filters for VAr and Harmonic Compensation," in Proc. IECON 02 Conf., Vol. 4, pp. 2495-2950, Nov. 2002.

[9] P. Salmerón, J. C. Montaño, J. R. Vázquez, J. Prieto, A. Pérez, "Compensation in Nonsinusoidal, Unbalanced Three-Phase Four-Wire Systems with Active Power Line Conditioner," IEEE Trans. Power Delivery, Vol. 19 (4), pp. 1968-1974, Oct. 2004.

[10]F. Z. Peng, "Applications Issues of Active Power Filters," IEEE Industry Applications Magazine, pp. 21-30, Sep. 1998. 